\title{
INCIDÊNCIA E DEFINIÇÃO DO ASSÉDIO MORAL ENTRE TRABALHADORES DO TRANSPORTE COLETIVO URBANO
}

Júlia Gonçalves

IMED

Suzana da Rosa Tolfo

Universidade Federal de Santa Catarina

Leonor Maria Cantera Espinosa

Universidade Autônoma de Barcelona

Thiago Soares Nunes

Universidade FUMEC/Centro Universitário UNA
Recebido em: 29/09/2019

$1^{\text {a }}$ revisão em: 04/03/2020

Aceito em: 20/05/2020

\section{RESUMO}

O estudo identificou a ocorrência e o conhecimento sobre Assédio Moral no Trabalho (AMT) para trabalhadores do transporte coletivo urbano de uma capital do Brasil. Foi realizado um estudo como misto, com 382 trabalhadores, que responderam um questionário de dados sociodemográficos, a Escala Laboral de Assédio Moral e a questões relacionadas ao conhecimento sobre essa violência. Os resultados demonstraram diferença entre o quantitativo de trabalhadores identificados como alvos de AMT pelos itens da escala (48,69\%) e aqueles que se reconhecem como assediados (36,34\%). A dimensão "condições de trabalho" foi a mais frequentemente citada na amostra. As definições de AMT relacionaram-se com humilhação, desrespeito e constrangimento. Apesar de terem conformidades conceituais com a literatura, estas categorias demonstraram um conhecimento simplificado, salientando elementos objetivos. Conclui-se que essa violência só poderá ser eficazmente com sua definição clara e distinta de outras formas de sofrimento decorrente do trabalho.

Palavras-chave: assédio moral no trabalho; transporte coletivo urbano; condições de trabalho. 


\section{INCIDENCE AND DEFINITION OF WORKPLACE BULLYING AMONG URBAN PUBLIC TRANSPORT WORKERS}

\section{ABSTRACT}

The study identified the occurrence and knowledge about Workplace Bullying (WB) for workers in urban public transport in a Brazilian capital. This mixed study was done, with 382 workers answered a sociodemographic data questionnaire, the Bullying Labor Scale and questions related to knowledge about this violence. The results showed a difference between the quantitative of workers identified as targets of WB by the items of the scale (48.69\%) and those who recognize themselves in this situation (36.34\%). The dimension "work conditions" was the most frequently mentioned in the sample. The definitions of WB were related to humiliation, disrespect and embarrassment. Despite having conceptual conformities with the literature, these categories demonstrated a simplified knowledge, emphasizing objective elements. It is concluded that violence can only be prevented with its clear and distinct definition from other forms of suffering in the workplace.

Keywords: workplace bullying; urban public transport; work conditions. 


\section{INCIDENCIA Y DEFINICIÓN DE ACOSO LABORAL ENTRE TRABAJADORES DEL TRANSPORTE PÚBLICO URBANO}

\section{RESUMEN}

El estudio identificó la ocurrencia y el conocimiento sobre el acoso laboral ( $A L$ ) en el para los trabajadores en el transporte público urbano en una capital brasileña. Se realizó un estudio mixto, con 382 trabajadores respondieron un cuestionario de datos sociodemográficos, la Escala Laboral de Acoso y preguntas relacionadas con el conocimiento sobre esta violencia. Los resultados mostraron una diferencia entre el cuantitativo de trabajadores identificados como objetivos de AL por los ítems de la escala (48.69\%) y aquellos que se reconocen como acosados (36.34\%). La dimensión "condiciones de trabajo" fue la más frecuente en la muestra. Las definiciones de AL estaban relacionadas con la humillación, la falta de respeto y la vergüenza. A pesar de tener conformidad conceptual con la literatura, estas categorías demuestran conocimiento simplificado, destacando elementos objetivos. Se concluye que esta violencia solo puede prevenirse con su definición clara y distinta de otras formas de sufrimiento resultantes del trabajo.

Palabras clave: acoso laboral; transporte público urbano; condiciones de trabajo. 


\section{INTRODUÇÃO}

Ao longo do desenvolvimento da humanidade, o trabalho tornou-se uma atividade central na vida das pessoas, constituinte da identidade e da subjetividade, além de um importante meio de socialização (Barreto \& Heloani, 2014; Borges \& Yamamoto, 2014; Dejours, 2007; Gonçalves \& Oliveira, 2017). O trabalho é um elemento-chave para compreender a atividade das pessoas na sua interação com o mundo (L. Freitas, 2013). O trabalho, para Blanch Ribas (2003) pode ser associado a significados positivos (prazer, reconhecimento), instrumentais (contrapartidas financeiras e formas de reconhecimento), e/ou negativos (sofrimento, violências, tortura). Ao adotar a concepção crítica ao neoliberalismo e às práticas de gestão, em que o foco é dado ao capital, é preciso reconhecer a alienação do trabalhador. Trata-se de um paradoxo, pois o trabalho não deveria ser um fator de sofrimento. Entre as situações negativas decorrentes do trabalho estão as violências, como é o caso do foco deste estudo, o assédio moral no trabalho (AMT) em trabalhadores do transporte coletivo urbano. Para subsidiar este estudo, porém, faz-se necessário antes retomar conceitos que o fundamentam.

A partir de 1980, a centralidade do trabalho é reafirmada com a intensificação da globalização, a reengenharia, as inovações tecnológicas, as possibilidades de comunicação, a exigência de trabalhos mais flexíveis e a constante preocupação com o realinhamento estratégico, a modernização de processos produtivos, financeiros e administrativos que acarretaram em uma contínua transformação nas organizações e nas relações laborais (Borges \& Yamamoto, 2014; Freitas, Heloani, \& Barreto, 2008; Heloani \& Barreto, 2018; Tolfo, 2015). Todos esses aspectos impactaram também nas esferas econômicas, sociais, culturais e tecnológicas relacionadas ao contexto do trabalho (Gonçalves \& Oliveira, 2017).

Esse cenário traz crescente flexibilização das relações de trabalho e desemprego, interesse em reduzir custos, grandes contingentes de demissões, terceirização, dessindicalizações, novas formas de contratos de trabalho, baixos salários e longas jornadas (Barreto, 2006; Barreto \& Heloani, 2014, 2015; Benfatti \& Dantas, 2017; Borges \& Yamamoto, 2014; Freitas et al., 2008) e implicam novos modelos de gestão organizacional (Nunes \& Tolfo, 2013). Esses, por sua vez, se mostram propícios à violência no trabalho, pois exigem dos trabalhadores versatilidade, flexibilidade, capacidade de constante adaptação às mudanças e para assumir desafios e riscos (Gonçalves \& Oliveira, 2017).

A violência no trabalho é entendida como um conjunto de atos que se distanciam de uma conduta razoável para a convivência e incluem agredir, ameaçar, prejudicar e ferir uma pessoa em seu trabalho. Um tipo de violência no trabalho é a psicológica que contempla táticas agressivas com o potencial de causar danos emocionais significativos nos alvos, o que inclui intimidação, assédio moral, coerção, abuso verbal e assédio sexual (Chappell \& Di Martino, 2006). 
O AMT, foco deste estudo, é um fenômeno tão antigo quanto o trabalho, mas é apenas no fim do século XX que ganha maior visibilidade como fator desencadeador de sofrimento no trabalho (Freitas et al., 2008; Martins \& Ferraz, 2014; Nunes, 2016; Soboll, 2015, 2017). O AMT tem atraído a atenção por ser um problema mundial e por ser caracterizado como um risco emergente que traz danos à saúde de todas as categorias de trabalhadores (Espinosa, Cantera, \& Pallarès, 2015; Organização Internacional do Trabalho [OIT], 2017; 2019).

Heinz Leymann (1990, 1996), considerado pioneiro nos estudos sobre o fenômeno, afirma que assédio moral ou "mobbing" no ambiente de trabalho ocorre quando a vítima é submetida a uma estigmatização sistemática por meio de injustiças e comunicação hostil e antiética que pode incapacitar alguém a encontrar emprego em sua área específica. A conceituação de AMT proposta por Einarsen, Hoel, Zapf e Cooper (2011) tratam-no como o ato de assediar, ofender, excluir alguém socialmente ou afetar negativamente as tarefas de trabalho, sendo esses comportamentos, individuais ou coletivos, repetidos de forma regular durante um período de tempo. Apesar dessa definição estar entre as mais utilizadas mundialmente, discordâncias entre as características específicas do fenômeno (Einarsen et al., 2011; Hirigoyen, 2015; Leymann, 1990, 1996; Soboll, 2017; Tolfo, 2011) revelam que ainda não há pleno consenso entre os autores sobre sua definição (Martins \& Ferraz, 2014).

A frequência/persistência e duração dos atos, com ocorrências repetidas e ao longo do tempo, assim como a exposição do alvo a comportamentos sociais negativos, como humilhação e hostilidade são consenso nas definições utilizadas para caracterizar o AMT (Einarsen et al., 2011; Hirigoyen, 2015; Leymann, 1990, 1996; Soboll, 2017; Tolfo, 2011). Porém aspectos como a percepção subjetiva do alvo, a identificação da intencionalidade nos atos do assediador, a presença de desequilíbrio e/ou abuso de poder e os prejuízos a saúde psíquica e física dos envolvidos ainda são características que geram discordância e carecem de demonstração por meio de investigações (Soboll, 2017).

O AMT foi introduzido na literatura brasileira com essa denominação em 2000. Alguns marcos desse processo são a tradução do livro da pesquisadora, psiquiatra e psicanalista francesa Marie France Hirigoyen (Hirigoyen, 2008) e a dissertação da médica Margarida Barreto (Barreto, 2000), que trazia a expressão "humilhações no trabalho" para designar o fenômeno (Barreto \& Heloani, 2014; Soboll, 2015). A primeira publicação brasileira com a utilização do termo "assédio moral no trabalho" é um ensaio teórico que, fundamentado nas ideias de Hirigoyen, analisa as "duas faces do poder perverso nas organizações modernas: o assédio moral e o sexual" (M. Freitas, 2001, p. 8).

Dentre as definições mais atuais, Heloani e Barreto (2018) - referências nos estudos sobre essa temática no Brasil e na América Latina, consideram além da relação entre agressor e vítima. Estes autores identificam uma causalidade relacionada com as formas de organizar o trabalho, as práticas organizacionais e 
a cultura organizacional, que visa humilhar e desqualificar o(s) alvo(s), de modo a degradar as condições de trabalho e atingir a dignidade do(s) indivíduo(s). Recentemente, a OIT (2019) publicou uma definição de AMT que corrobora com a dos autores acima citados, considerando um conjunto de comportamentos (ou ameaças) e práticas inaceitáveis que se destinam a causar (e é provável que causem) danos físico, psicológico, sexual e/ou econômico.

No que concerne à definição jurídica sobre o AMT, não existe no Brasil uma lei federal específica sobre o tema (Heloani \& Barreto, 2018). Contudo, leis específicas estaduais, tais como no Distrito Federal (Lei n. 2949 - 2002), em Minas Gerais (Lei Complementar n. ${ }^{\circ} 116$ - 2011), no Rio Grande do Sul (Lei n. ${ }^{\circ}$ 12561 - 2006) e em São Paulo (Lei n. ${ }^{\circ} 12250$ - 2006), versam sobre a conceitualização e características, sistema de denúncia, apuração e punição da prática, e sistema de prevenção e apoio às vítimas de assédio (Nogueira, Nunes, Carvalho Neto, \& Ferreira, 2019). Ademais, no ambiente jurídico existe unanimidade no entendimento de que a prática de AMT é um ato ilícito, e sua interpretação se baseia principalmente nos itens relativos à igualdade e dignidade humana pelos dispositivos da CLT (art. 483), do Código Penal (arts. 138, 139, 140 e 146, do Código Civil (arts. 186 e 187) e da Constituição (art. $1^{\circ}$ inc. III, art. 5, inc. II e III) (Heloani \& Barreto, 2018).

Pesquisas já demonstraram as relações e repercussões entre contexto e condições de trabalho, práticas organizacionais e características pessoais e laborais que podem influenciar na prática do AMT (Jacoby \& Monteiro, 2014; Nunes, 2016; Nunes \& Tolfo, 2013; Pooli \& Monteiro, 2018; Rigotto, Maciel \& Borsoi, 2010; Rodrigues \& Freitas, 2014). A pesquisa de Rigotto et al. (2010) indicou que as práticas de violência conduzidas por indivíduos investidos de poder e autoridade transcendem as relações interpessoais, estando relacionadas às políticas de gestão organizacional centradas no estabelecimento de metas de produção a serem cumpridas pelos trabalhadores. Corroborando, Nunes (2016) afirma que traços culturais presentes na sociedade são encontrados dentro das organizações e facilitam a ocorrência do AMT. O autor identificou, a saber: impunidade (a violência é legitimada, com uma mensagem de que "tudo é permitido"); proximidade do grupo dominante (dependendo do grupo de vínculo ou de relações mais próximas, pode sofrer sanções ou ser protegido pelos pares quando realizar ato ilícito/violento); categoria a qual pertence (em um ambiente universitário, por exemplo, os docentes detêm mais poder, e os técnicos administrativos são vistos como "servis").

Neste estudo, o AMT foi investigado com trabalhadores de Transporte Coletivo Urbano (TCU). A segurança e o bem-estar desses trabalhadores estão estreitamente interligados com a segurança e o bem-estar dos passageiros e demais usuários das vias (Glasø, Bele, Nielsen, \& Einarsen, 2011; Silveira, Abreu, \& Santos, 2014; Zhou, Boyer, \& Guay, 2018). Há estudos sobre a violência no trabalho desses trabalhadores, porém essa é destacadamente investigada e percebida como reflexo da violência urbana e do contexto social (Alves \& Paula, 
2009; Assunção \& Medeiros, 2015; Geoffrion et al., 2017; Kornig, Chanut-Guieu, Domette, Louit-Martinod, \& Méhaut, 2017; Lincoln \& Gregory; 2015; PaesMachado \& Levenstein, 2002; Sampaio, Coelho, Barbosa, Mancini, \& Parreira, 2009; Zhou et al., 2018). Apenas o estudo de Glasø et al. (2011), realizado na Noruega, retrata a exposição de motoristas de ônibus especificamente ao AMT.

O AMT, segundo a Organização Mundial da Saúde (OMS, 2017), e suas formas de expressão - tais como intimidação, humilhação e hostilização, são causas recorrentes de adoecimento e riscos para a saúde dos trabalhadores, tanto físicos como psicológicos, e impactam nas relações familiares e sociais, nas empresas e na sociedade. Somado a isso, a OIT (2019) reconhece que o AMT pode constituir uma violação ou um abuso dos direitos humanos, pois se constitui em ameaça para a igualdade de oportunidade e incompatível com o trabalho decente. Assim, por meio de um estudo misto (quanti-quali) identificou-se a ocorrência e o conhecimento acerca do AMT em trabalhadores de TCU de uma capital da região sul do Brasil.

\section{MÉTODO}

\section{PARTICIPANTES}

Participaram 382 trabalhadores (motoristas, cobradores, trabalhadores administrativos e da manutenção/conservação de TCU) associados ao Sindicato dos Trabalhadores em Empresas de Transportes Coletivos e Seletivos Urbanos de Passageiros de uma capital da região sul do Brasil, a qual forneceu a anuência para realização da pesquisa. Trata-se de uma amostra não probabilística por conveniência, sendo que os critérios de inclusão se pautaram na disponibilidade institucional e no consentimento do participante. Excluiu-se da amostra trabalhadores com menos de seis meses de trabalho na atual empresa de TCU.

\section{INSTRUMENTOS}

Os dados foram coletados com a utilização dos seguintes instrumentos:

- Questionário de Dados Sociodemográfico, com perguntas sobre sexo, idade, estado civil, escolaridade, tempo de trabalho, jornada diária de trabalho e funções desempenhadas.

- Escala Laboral de Assédio Moral - ELAM (Rueda, Baptista, \& Cardoso, 2015) composta de três fatores: Fator 1 : Condições de trabalho (com 11 itens, $\alpha=0,85$ ), Fator 2: Humilhação (8 itens, $\alpha=0,87$ ) e Fator 3: Preconceito ( 8 itens, $\alpha=0,82$ ). A ELAM totaliza 27 itens respondidos a partir das opções "nunca"; "poucas vezes"; "muitas vezes" e "sempre", pontuados de um a quatro, respectivamente.

- Entrevista com roteiro semiestruturado, composta por três questões de escolha forçada (sim ou não): "Você sabe o que é assédio moral?", "Você acredita que já 
foi vítima de assédio moral no atual emprego?" e "Você já presenciou situações de assédio moral com colegas?" e uma questão aberta e descritiva: "Se você pudesse dizer, brevemente, o que é assédio moral, como explicaria?".

\section{PROCEDIMENTOS ÉTICOS E DE COLETA DOS DADOS}

Com o Termo de Consentimento Institucional assinado pelos representantes do sindicato, a pesquisa foi submetida ao Comitê de Ética em Pesquisa com Seres Humanos (CEPSH) da Universidade Federal de Santa Catarina, de acordo com a resolução do Conselho Nacional de Saúde n० 466/12, e aprovado sob o Certificado de Apresentação para Apreciação Ética n 1.789.878.

A pesquisa foi divulgada no jornal do sindicato, nas reuniões e assembleias da categoria. As aplicações dos instrumentos ocorreram durante a jornada de trabalho, no intervalo, no início ou no final do turno, entre os meses de janeiro e março de 2017, em duas assembleias da categoria, duas garagens de empresas e em cinco terminais de integração da capital do sul do país. A abordagem para explicar os objetivos da pesquisa aos trabalhadores foi realizada individualmente, pela primeira autora deste estudo, e àqueles que aceitaram participar foi fornecido o Termo de Consentimento Livre Esclarecido. Os três instrumentos utilizados foram aplicados em sequência e a pesquisadora teve a preocupação com a privacidade dos participantes, dando-Ihes espaço para que se sentissem à vontade ao mesmo tempo que pudessem esclarecer possíveis dúvidas.

\section{ANÁLISE DOS DADOS}

Para a tabulação e organização das informações e o desenvolvimento do banco de dados utilizou-se o Excel e, posteriormente, o software Statistical Package for the Social Sciences (SPSS) versão 23 para a proceder estatística descritiva e inferencial (teste Mann-Whitney). Inicialmente, realizou-se a inspeção do banco de dados, utilizando análises estatísticas descritivas para aferir a coerência das informações, como erros de digitação. Foram identificados casos omissos nos itens da escala - cinco itens em três formulários. Dado que a pesquisa permitia a não resposta aos itens, optou-se por substituir essas não respostas pelo valor da média em cada um dos itens. As demais análises descritivas foram realizadas somente com os casos válidos para cada variável. O questionário de dados sociodemográficos foi utilizado com fins de caracterização da amostra e foi identificada a frequência e porcentagem das respostas válidas para cada variável.

A partir análise da ELAM (medidas de tendência central, dispersão e frequência) e do referencial teórico adotado, foram criadas duas categorias: "Não sofreu assédio moral" e "Alvo de assédio moral". Para essa classificação considerou-se que, se o participante marcasse em um ou mais itens da ELAM as opções de respostas "muitas vezes" ou "sempre" (pontuação três e quatro na escala) caracterizava-se "Alvo de assédio moral", uma vez que não é o número de comportamentos negativos que o define e sim sua frequência e persistência. 
Assim, foi possível conhecer a incidência do AMT no grupo de trabalhadores de TCU pesquisado por meio de uma medida objetiva (quantitativa).

A entrevista com roteiro semiestruturado foi utilizada para investigar o conhecimento da definição e a percepção de exposição dos participantes ao AMT. Foram analisadas averiguando frequência e porcentagem de resposta a cada variável. Com isso, pode-se identificar uma medida subjetiva de AMT, que permitiu saber quantos participantes sentiam-se assediados, com base em sua percepção e seu conhecimento (Jacoby \& Monteiro, 2014). Já para a questão aberta "Se você pudesse dizer, brevemente, o que é assédio moral, como explicaria?", foi realizada uma análise (qualitativa) de conteúdo categorial (Bardin, 2011). As respostas foram triadas, excluídas aquelas que não tiveram relação com a pergunta, e categorizadas após a análise.

\section{RESULTADOS}

A caracterização dos participantes é descrita na Tabela 1. A idade média dos participantes foi de 36,98 anos (Md = 37; DP = 10,11; Mín. = 19; Máx. = 71), tendo exercido suas atividades nas empresas de transporte coletivo urbano de passageiros por um período de 6 mês a 30 anos com tempo médio de empresa de 8,45 anos ( $M d=6 ; D P=7,24 ;$ Mín. = 0; Máx. = 30), e o tempo médio na função foi de 6,43 anos (Md = 5; DP = 6,53; Mín. = 0; Máx. = 30).

Tabela 1.

Análise descritiva para as variáveis sociodemográficas.

\begin{tabular}{ccccc} 
Variáveis & Categorias & Frequência $(\boldsymbol{n})$ & Porcentagem $(\%)$ \\
\cline { 2 - 3 } Sexo & Masculino & 340 & 89,24 \\
& Feminino & 41 & 10,76 \\
\hline Estado Civil & Solteiro & 135 & 36,10 \\
& Casado & 212 & 56,68 \\
& Divorciado ou Viúvo & 27 & 7,22 \\
\hline \multirow{2}{*}{ Escolaridade } & 1o Grau Incompleto & 37 & 10,66 \\
& 1o Grau Completo & 38 & 10,95 \\
& 2o Grau Incompleto & 39 & 11,24 \\
& 2o Grau Completo & 198 & 57,06 \\
& Curso Técnico & 5 & 1,44 \\
& Graduação Incompleta & 18 & 5,19 \\
& Graduação Completa & 12 & 3,46 \\
\hline
\end{tabular}


Tabela 1. Continuação.

\begin{tabular}{cccc} 
Variáveis & Categorias & Frequência $(\boldsymbol{n})$ & Porcentagem $(\%)$ \\
Função na & Motorista & 185 & 48,43 \\
Empresa & Cobrador & 173 & 45,29 \\
& Outras & 24 & 6,28 \\
\hline \multirow{2}{*}{ Turno de } & Matutino & 190 & 51,91 \\
Trabalho & Vespertino & 118 & 32,24 \\
& Noturno & 58 & 15,85 \\
\hline Horas & De 6 a 7 horas & 254 & 69,21 \\
Trabalhadas & De 7 a 8 horas & 88 & 23,98 \\
& De 8 a 9 horas & 25 & 6,81 \\
\hline
\end{tabular}

Os resultados da análise descritiva do escore geral da Escala Laboral de Assédio Moral (ELAM) e de suas dimensões podem ser observados na Tabela 2. O escore geral apresentou a média de 35,71 (DP = 9,31). Entre as dimensões, "Condições de trabalho" apresentou a média mais elevada, seguida de "Preconceito" e Humilhação.

Tabela 2.

Valores descritivos dos escores da Escala Laboral de Assédio Moral (ELAM).

\begin{tabular}{c|c|c|c|c|c} 
Variáveis & M & Md & DP & Mín & Máx \\
Escore Geral & 35,71 & 33 & 9,13 & 27 & 83 \\
Condições de Trabalho & 16,56 & 15 & 5,42 & 11 & 42 \\
Humilhação & 8,83 & 8 & 1,47 & 8 & 17 \\
Preconceito & 10,32 & 9 & 3,53 & 8 & 29 \\
\hline
\end{tabular}

Nota. $\mathrm{N}=382$ (amostra total da pesquisa); M: média; Md: mediana; DP: desvio padrão; Mín: mínimo; Máx: máximo.

A distribuição da frequência de respostas, a média e desvio padrão dos itens da ELAM pode ser observada na Tabela 3. Os itens que obtiveram frequências de respostas "muitas vezes" e "sempre" acima de $10 \%$ são pertencentes, em sua maioria, à dimensão "Condição de trabalho". Os itens assinalados em itálico foram os que demonstram maiores médias (variando de 1,46 a 1,84) e também maiores desvios-padrão (variando entre 0,75 a 1,05), excluindo esses itens, os desvios-padrão dos itens foram baixos (variando entre 0,17 e 0,73), o que indica homogeneidade e concordância nas respostas dos participantes a esses itens. 
Tabela 3.

Distribuição da frequência de respostas, Média e Desvio Padrão dos itens da ELAM.

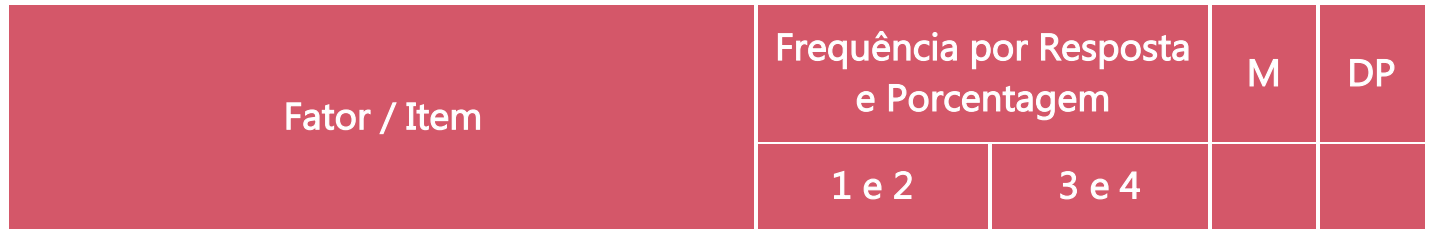

Condições de Trabalho

1. Tenho que pedir autorização para ir

$324(84,82) \quad 58(15,18) \quad 1,65 \quad 1,03$

embora, mesmo já passado meu horário.

3. Sou pressionado(a) a cumprir horários e viagens.

6. Sou pressionado(a) a fazer hora extra. $\quad 353(9,41) \quad 29(7,59) \quad 1,38 \quad 0,71$

7. Sou advertido(a) publicamente quando $334(87,43) \quad 48(12,57) \quad 1,58 \quad 0,88$ chego atrasado(a).

9. Me ligam para saber onde estou e/ou o $358(93,72) \quad 24(6,28) \quad 1,36 \quad$ 0,68 que estou fazendo.

12. Se saio mais cedo, no outro dia sou advertido(a) publicamente.

14. Recebo informações

confusas/imprecisas.

16. Recebo a culpa pelo erro dos outros.

21. Meu horário de intervalo é desrespeitado.

22. Sou obrigado(a) a fazer tarefas que não são da minha responsabilidade.

25. Sou obrigado(a) a fazer trabalhos contra a minha vontade.

$299(78,27) \quad 83(21,73) \quad 1,84 \quad 1,05$

$359(93,98) \quad 23(6,02) \quad 1,28 \quad 0,68$

$331(86,65) \quad 51(13,35) \quad 1,67 \quad 0,79$

$339(88,74) \quad 43(11,26) \quad 1,54 \quad 0,76$

$330(86,39) \quad 52(13,61) \quad 1,65 \quad 0,78$

$358(93,72) \quad 24(6,28) \quad 1,35 \quad 0,64$

$367(96,07) \quad 15(3,93) \quad 1,27 \quad 0,66$

\section{Humilhação}

2. Colocam em dúvida minha

$376(98,72) \quad 6(1,28) \quad 1,08 \quad 0,37$

masculinidade/ feminilidade.

5. Sou excluído(a) devido a minha

$379(99,48) \quad 3(0,52) \quad 1,05 \quad 0,26$ cor/raça.

10. Sou desqualificado(a) devido a(s) minha(s) tatuagem(s) e/ou piercing(s).

$378(98,96) \quad 4(1,04) \quad 1,05 \quad 0,30$

13. Sou ameaçado(a) de violência física.

$363(95,03) \quad 19(4,97) \quad 1,24 \quad 0,53$ 
Tabela 3. Continuação.
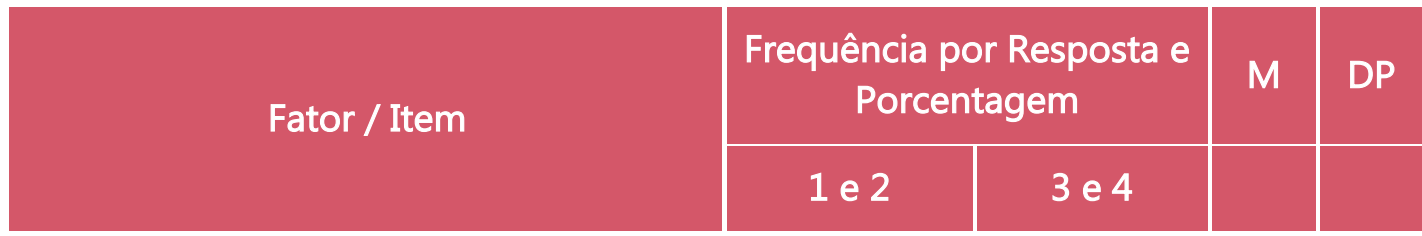

18. Sofro preconceito devido a minha $380(99,48)$

$2(0,52)$

$1,03 \quad 0,24$ opção sexual.

20. Sou desqualificado(a) devido ao $380(99,48) \quad 2(0,52) \quad 1,02 \quad 0,17$ meu sexo.

24. Meus problemas pessoais são expostos publicamente.

$372(97,38) \quad 10(2,62) \quad 1,25 \quad 0,63$

26. Sou ameaçado(a) por meio de ligações telefônicas.

$$
376(98,43) \quad 6(1,57) \quad 1,12 \quad 0,48
$$

\section{Preconceito}

4. Sou excluído(a) das conversas em $367(96,07) \quad 15(3,93) \quad 1,26 \quad 0,58$ grupo.

\section{Espalham boatos sobre minha vida pessoal.}

11. Sou exposto(a) de maneira constrangedora.

15. Sou alvo de deboche devido a minha forma de ser.

17. Quando me aproximo fazem gestos de desprezo.

19. Criticam o meu trabalho de forma injusta e/ou exagerada.

$\begin{array}{llll}337(88,22) & 45(11,78) & 1,46 & 0,80 \\ 360(94,24) & 22(5,76) & 1,29 & 0,59 \\ 362(94,76) & 20(5,24) & 1,29 & 0,58 \\ 371(97,12) & 11(2,88) & 1,15 & 0,46 \\ 353(92,41) & 29(7,59) & 1,42 & 0,73 \\ 367(96,08) & 15(3,92) & 1,27 & 0,67 \\ 372(97,38) & 10(2,62) & 1,19 & 0,60\end{array}$

23. Fazem comentários

maldosos/humilhantes a meu respeito.

27. Minha presença é ignorada.

Nota. $\mathrm{N}=382 ; 1$ : nunca; 2: poucas vezes; 3: muitas vezes; 4: sempre; $\mathrm{M}=$ média; $\mathrm{DP}=$ Desvio Padrão.

A partir da análise da ELAM, considerou-se os participantes que em um ou mais itens assinalaram as opções de respostas "muitas vezes" ou "sempre" (pontuação três e quatro na escala) como alvos de AMT, o que representou $48,69 \%$ amostra.

$\mathrm{Na}$ Tabela 4, a seguir, estão os dados relacionados ao conhecimento do conceito e à vivência de situações de AMT. Além de $89,50 \%$ dos participantes terem declarado conhecer o significado do termo "Assédio moral", 36,34\% declarou ter sido alvo e $60,06 \%$ afirmou já ter presenciado outros colegas sofrendo esse tipo de violência. 
A comparação dos escores da ELAM entre indivíduos que declararam possuir ou não conhecimento sobre a definição de assédio moral não demonstrou diferença significativa $(U=0,09 ; p=0,92)$. Ao analisar os escores da ELAM, as pessoas que se autorrelataram como alvos de AMT obtiveram escores mais altos na escala $(U$ $=10,08 ; p<0,001$ ), ou seja, quem identifica-se como vítima também marcou mais situações de assédio descritas da escala dos que não se consideram alvos dessa violência. A identificação de que $60,06 \%$ dos trabalhadores já presenciaram outros colegas sofrendo AMT é preocupante. Esses participantes também obtiveram escores significativamente maiores na $\operatorname{ELAM}(U=7,12 ; p<0,001)$ do que os que não presenciaram a violência com terceiros, outro indicativo do reconhecimento do problema.

\section{Tabela 4.}

Descrição da frequência das respostas dos participantes sobre seu conhecimento e vivências de assédio moral no ambiente de trabalho.

\begin{tabular}{c|c|c|c}
\hline Variáveis & Categorias & $\begin{array}{c}\text { Frequência } \\
(\boldsymbol{n})\end{array}$ & $\begin{array}{c}\text { Porcentagem } \\
(\%)\end{array}$ \\
Sabe o que é assédio moral? & Sim & 324 & 89,50 \\
& Não & 38 & 10,50 \\
\hline Já foi vítima de assédio moral? & Sim & 129 & 36,34 \\
\hline Já presenciou colegas sofrendo & Não & 226 & 63,66 \\
assédio moral? & Sim & 212 & 60,06 \\
\hline
\end{tabular}

Apesar de grande parte dos participantes $(\mathrm{N}=324)$ ter declarado conhecer o significado do conceito AMT, ao realizar-se uma análise detalhada das respostas foi identificado que 93 destes participantes deixaram a questão "Se você pudesse dizer, brevemente, o que é assédio moral, como explicaria?" em branco, supondo não ter conhecimento claro e preciso acerca do fenômeno para que pudesse explicá-lo. Não é possível afirmar os motivos para tanto, mas pode se conjecturar sobre conhecimento parcial ou dificuldade em elaborar o conceito.

Dos 231 participantes que responderam à questão sobre a definição, em uma análise de conteúdo categorial (Bardin, 2011) foram excluídas 21 respostas por não terem relação com a pergunta ou apenas repetirem "é assediar moralmente uma pessoa", "é falar dos outros" e "quando acontece algo que não gostamos" . As 210 respostas restantes levaram à identificação de 10 categorias, conforme apresentado na Tabela 5, sendo que muitas das respostas foram enquadradas em mais de uma categoria.

A definição de AMT para os respondentes está associada principalmente à humilhação, ao desrespeito, ao abuso de poder e à exposição pública, como nos 
exemplos relativos aos dois primeiros: "é a exposição de alguém a situações humilhantes e constrangedoras, repetitivas e prolongadas durante a jornada de trabalho" e "é quando [...] me levam ao constrangimento, deturpando a minha autoestima, me tornando diante dos outros como incapaz". A relação do fenômeno com abuso de poder e/ou autoridade foi associado com hierarquia, como em: "é feito por uma pessoa que tem um cargo superior ao seu, e usam isso para te intimidar, ameaçar e muitas vezes, te humilhar publicamente". Nesta última resposta há ainda associação com outras duas categorias: a ameaça e/ou intimidação e ser exposto publicamente.

\section{Tabela 5.}

Categorias geradas a partir da análise de conteúdo, palavras-chave e número de evocações que a representam.

\begin{tabular}{|c|c|c|}
\hline Categorias & Palavras-chave & $\begin{array}{l}\text { Frequência } \\
\qquad(n)\end{array}$ \\
\hline Humilhação & $\begin{array}{l}\text { Humilhar, ofender, minimizar, denegrir, } \\
\text { atentar contra a dignidade, rebaixar, expor a } \\
\text { situações humilhantes }\end{array}$ & 57 \\
\hline Desrespeito & $\begin{array}{l}\text { Desrespeitar, falta de respeito, prejudicar o } \\
\text { trabalho e/ou vida pessoal e/ou autoestima, } \\
\text { tratar com desigualdade }\end{array}$ & 52 \\
\hline Constrangimento & $\begin{array}{l}\text { Constranger, desqualificar, fazer funções } \\
\text { e/ou tarefas que não são sua } \\
\text { responsabilidade, ser motivo de } \\
\text { piada/brincadeira/apelidos }\end{array}$ & 42 \\
\hline $\begin{array}{l}\text { Abuso de poder } \\
\text { e/ou autoridade }\end{array}$ & $\begin{array}{l}\text { Intimidar, usar de poder/autoridade, cobrar } \\
\text { exageradamente, ameaçar demissão, coação }\end{array}$ & 46 \\
\hline $\begin{array}{l}\text { Ameaça e/ou } \\
\text { intimidação }\end{array}$ & $\begin{array}{c}\text { Grosserias, gritos, ameaças, chantagem, } \\
\text { perseguir }\end{array}$ & 35 \\
\hline Exposição pública & $\begin{array}{l}\text { Ser chamado a atenção ou receber atitude } \\
\text { inadequada na frente aos demais, difamar }\end{array}$ & 45 \\
\hline $\begin{array}{l}\text { Preconceito e } \\
\text { discriminação }\end{array}$ & $\begin{array}{l}\text { Tratamento diferenciado pela cor, raça, sexo, } \\
\text { aparência, escolha sexual, opção religiosa }\end{array}$ & 19 \\
\hline $\begin{array}{l}\text { Pressão nas } \\
\text { atividades de } \\
\text { trabalho }\end{array}$ & $\begin{array}{c}\text { Ser pressionado quanto ao tempo e } \\
\text { atividade de trabalho, ser pressionado } \\
\text { publicamente, ser obrigada a fazer algo } \\
\text { contra seu gosto }\end{array}$ & 19 \\
\hline $\begin{array}{l}\text { Exclusão e/ou ser } \\
\text { ignorado }\end{array}$ & $\begin{array}{l}\text { Ser ignorado, evitar contato, não conversar, } \\
\text { sair de perto }\end{array}$ & 9 \\
\hline Assédio sexual & $\begin{array}{c}\text { Cantadas, falta de respeito, querer } \\
\text { ficar/beijar/sexo, dar em cima }\end{array}$ & 17 \\
\hline
\end{tabular}


Ainda foi possível identificar relações com preconceito e discriminação, ser pressionado no desenvolvimento das atividades de trabalho e ser excluído e/ou ignorado. Em 17 respostas houve associação direta ao assédio sexual, indicando confusão entre conceitos ou frequência do mesmo, como em: "quando você é exposto a constrangimento por cantadas, falta de respeito, onde não respeitam o próximo e querem ficar, beijar, sexo e outros" e "é quando alguém fica dando em cima de outra pessoa".

\section{DISCUSSÃO}

Trabalhadores de TCU constituem uma categoria profissional importante tanto por formarem um contingente numeroso de trabalhadores expostos a circunstâncias de trabalho particulares, como pela responsabilidade coletiva da atividade e pela crescente urbanização nas sociedades. Frente a isso, a organização e as condições de trabalho no TCU são capazes de afetar tanto a qualidade de vida dos centros urbanos (Battiston, Cruz, \& Hoffmann 2006), quanto a saúde e bem-estar dos próprios trabalhadores.

Ao analisar resultados da ELAM, o fator "condições de trabalho" foi o mais frequente e refere-se às dificuldades enfrentadas no exercício das funções de trabalho, tais como tarefas fora do escopo da função e contra a vontade, pressão e controle demasiado e indevido sobre o trabalho, desrespeito e exposição pública como forma de punição, entre outras, em conformidade com estudo de Rueda et al. (2015). Estes aspectos demonstram que esses profissionais estão sujeitos a pressões e estresses decorrentes, de modo especial, de práticas de gestão com práticas funcionalistas e autoritárias, o que vai ao encontro da crítica de Gaulejac (2007) da gestão como doença social. A administração ocorre por meio de práticas que privilegiam o autoritarismo e o controle de modo exacerbado. além disso, trata-se de um trabalho que ocorre, principalmente, fora dos muros da empresa e em contato constante com clientes/passageiros e demais pessoas que utilizam as vias da cidade. As peculiaridades das atividades desses trabalhadores, em especial motoristas e cobradores, coloca-os sob constante pressão para cumprir horários das linhas, independentemente das intempéries ou congestionamentos que possam ocorrer em seu trajeto. Somado a isso, como o trabalho é desenvolvido nas ruas, são chamados a atenção nos próprios terminais do ônibus, frente a colegas e passageiros.

Embora problemas nas condições de trabalho não estejam "par e passo" com assédio moral a degradação dessas condições de trabalho mostram-se muito propícias para sua ocorrência (Tolfo, 2011). A deterioração proposital das condições de trabalho, proposta por Hirigoyen (2015), está dentre as categorias de atitudes hostis identificadas pelos participantes assediados, e incluem retirar do alvo a autonomia; não transmitir informações úteis e claras; atos de contestação sistemática das decisões tomadas pelo alvo; críticas desproporcionais, inadequadas e injustas ao trabalho; privação do acesso aos instrumentos de trabalho; delegação de tarefas aquém da capacidade ou 
impossíveis de serem cumpridas, dentre outros exemplos. Situações que estão diretamente relacionados a itens que obtiveram elevada frequência da ELAM, como: "Tenho que pedir autorização para ir embora, mesmo já passado meu horário" (privação de autonomia) e "Recebo informações confusas e imprecisas" (informações confusas e desnecessárias).

Os resultados evidenciam o que foi verificado em revisão de Rai e Agarwal (2017), segundo os quais dentre os aspectos que antecedem o AMT estão as más condições de trabalho, a carga de trabalho, o conflito, a ambiguidade de papéis, a coesão de grupo, a percepções de segurança, o apoio social no trabalho e a exaustão emocional. Reiteram aspectos que já haviam sidos evidenciados por Couto, Lawoko e Svanstrom (2009) ao identificarem que condições de trabalho, tais como horas e turno de trabalho, trabalhar sozinho, trabalhar em ambientes públicos, alta carga de trabalho e mudanças organizacionais, comuns no contexto do TCU, são fatores potenciais para aumentar a exposição e o risco de violência no trabalho.

As respostas mais frequentemente citadas na subcategoria "preconceito", conforme o ELAM, são relacionadas a ser excluído ou ignorado em conversas, uso de gestos de desprezo e comentários maldosos/humilhantes. Verifica-se, assim, a recusa de comunicação e outras formas de comunicação que demonstram humilhação e/ou atentado contra a dignidade (Hirigoyen, 2015).

Especificamente sobre Humilhação, os resultados mais frequentemente identificados pelos trabalhadores do transporte coletivo urbano foram a exclusão devida à raça, questões ligadas a sexualidade/gênero. Essas situações relacionadas a atentado contra a dignidade parecem remeter a brincadeiras que colocam em dúvida a sexualidade/gênero dos participantes, o que muitas vezes é uma estratégia utilizada em países com cultura machista em um setor predominantemente masculino.

Ao considerarmos que o assédio moral é uma forma de violência no trabalho, se identifica o privilégio de estudos desta última sobre trabalhadores de transporte coletivo, sem especificar o primeiro. Couto et al. (2009) verificaram que $64,4 \%$ dos participantes relataram ter sofrido violência no local de trabalho nos últimos 12 meses, sendo mais frequentes o abuso e agressão verbal, experiências desagradáveis e agressões. Já no estudo de Sampaio et al. (2009) 75,3\% dos motoristas e cobradores participantes relataram ter sofrido algum tipo de violência no local de trabalho. Para Lincoln e Gregory (2015) violência no contexto de trabalho do transporte coletivo tende a ser mais verbal do que física, embora isso não seja menos prejudicial aos trabalhadores.

A identificação de que mais da metade dos trabalhadores já presenciaram outros colegas sofrendo AMT é preocupante. Mesmo que esse aspecto não tenha sido intuito desta investigação, é possível inferir, a partir da análise dos dados, uma indicação de violência moral como uma estratégia organizacional, pois, além de vítimas, são testemunhas de situações de violência (Jacoby \& Monteiro, 2014). 
Além disso, considerando que a literatura demonstra o transbordamento às quais as testemunhas de assédio também estão sujeitas, significa que as consequências negativas desse mal estar irá atingir também os colegas de trabalho. Tais resultados vão ao encontro do de outros estudos que também identificaram os participantes como testemunhas da violência no trabalho com colegas, como por exemplo Zhou et al. (2018) que afirmou que motoristas de ônibus são frequentemente expostos a eventos e incidentes violentos no trabalho antes de serem vítimas. No estudo de Pooli e Monteiro (2018), 33,6\% dos participantes afirmaram que já observaram ou testemunharam alguma situação de AMT, e, na pesquisa de Jacoby e Monteiro (2014), 34,1\% afirmaram ter presenciado atos abusivos no trabalho nos últimos seis meses. Nunes, Tolfo e Nunes (2014) relatam que mesmo aqueles que observam a violência a outrem, também podem apresentar consequências, como por exemplo, desmotivação com o trabalho, queda de produtividade e até medo de ser a próxima vítima.

Chama a atenção o resultado da medida objetiva, por meio dos itens da ELAM, que apontou que $48,69 \%$ dos trabalhadores vivenciaram comportamentos hostis de AMT. Esse percentual demonstra o elevado número de atingidos diretamente pelo problema. A utilização dessa escala, cujas evidências psicométricas anteriores não a tornam um instrumento imune a vieses, alerta para situações frequentes no meio laboral. Em complemento, a medida subjetiva de análise apresentou que $36,34 \%$ dos trabalhadores reconheceram-se como alvos de AMT e reforça a necessidade de repensar as condições, a organização do trabalho e as práticas gerenciais utilizadas nesta categoria. O resultado deste estudo é ainda mais preocupante do que o achado por Glasø et al. (2011) ao examinarem a exposição dos motoristas de ônibus noruegueses a essa violência, em que revelaram que $11,6 \%$ dos entrevistados se identificaram como alvos e com isso, os autores já afirmaram que essa pode ser uma ocupação de alto risco ao AMT.

A diferença entre trabalhadores identificados pelos itens da ELAM como alvos e aqueles que se reconhecem nessa situação, corroboram com os resultados de outros estudos que também apontam uma frequência menor de pessoas que se reconhecem como vítimas do que as que são identificadas por meio dos resultados no instrumento objetivo (Jacoby \& Monteiro, 2014; Pooli \& Monteiro, 2018). Estes resultados levam a questionar se na prática esta diferença demonstra a existência de um percentual elevado de testemunhas do assédio ou se a possível ocorrência de assédio moral organizacional naturalizado e a preocupação com qualquer forma de identificação podem ter levado a que diversos respondentes não tenham se identificado como alvos diretos.

Os significados subjetivos que os indivíduos atribuem às suas experiências relacionadas ao trabalho são moldados pelos ambientes institucionais e pelas comunidades ocupacionais onde interagem (Glasø et al., 2011), refletindo o contexto social e econômico no qual os trabalhadores estão inseridos. Frente a isso, a prevenção do AMT só poderá ser eficaz quando sua definição for clara e distinta de outras formas de sofrimento no local de trabalho (Hirigoyen, 2004). 
Ao analisar o conhecimento acerca da definição de AMT, foram consideradas as respostas e identificadas as categorias, sendo as mais frequentes a humilhação, o desrespeito e o constrangimento, aspectos presentes na literatura acerca do AMT (Freitas et al., 2008; Heloani \& Barreto, 2018). A partir da análise das respostas foi possível identificar que o conhecimento do AMT é limitado e simplificado, pois salienta elementos objetivos, de fácil identificação e manifestos visivelmente. Contudo, essa violência remonta a formas mais amplas, por vezes sutis e enraizadas nos relacionamentos estabelecidos no trabalho, englobando elementos subjetivos relacionados à ofensa à dignidade humana e que trazem prejuízos e danos aos trabalhadores (Tolfo, 2011; Soboll, 2017). Os trabalhadores identificam os atos hostis (Hirigoyen, 2015) no ambiente de trabalho, mas não há associação ao caráter processual do fenômeno, que pressupõe continuidade e frequência.

A incompreensão acerca do AMT pode levar à banalização e à má interpretação do significado e alcance do problema. Não obstante, tal tema não é de conhecimento tácito entre a população, sendo, muitas vezes, o conceito utilizado de forma errônea nas relações de trabalho (Nunes, Tolfo, \& Espinosa, 2018). Apesar do necessário cuidado na definição do fenômeno, pode-se incorrer em uma tendência de generalização, de forma que situações desagradáveis no trabalho, tais como conflitos ou situações eventuais de dano, ou que apresentem repercussões na saúde física ou mental dos trabalhadores costumam ser nomeadas como assédio moral (Rodrigues \& Freitas, 2014).

Apesar do limitado conhecimento sobre AMT entre trabalhadores de uma categoria altamente politizada e sindicalizada, reitera-se a importância da prevenção e assistência aos alvos, assim como um cuidado as pessoas que compartilham o sofrimento do assediado. Informações sobre a definição, formas de identificação, comportamentos negativos caracterizadores, as consequências tanto para indivíduo, família, organização e sociedade -, bem como onde procurar auxílio deverem ser de domínio público, tanto para indivíduos quanto para profissionais técnicos da saúde ou gestão de pessoas nas organizações. As diferentes instituições que recebem demandas de AMT - sejam jurídicas, de gestão ou saúde e, em especial, as públicas -, precisam elaborar fluxos e protocolos de atendimento e compor equipes tecnicamente preparadas para atender esses casos. Essas demandas, tanto individuais quanto coletivas, precisam de suporte, seja ao atendimento de queixas de assédio interpessoal ou para intervir em organização que precisam rever e adequar suas formas de gestão.

Frente a esse cenário, cabe às organizações do trabalho elaborarem políticas e práticas de gestão de pessoas que inibam e não tolerem um contexto de violência no trabalho, indicando qual o comportamento aceitável, além de instruir, treinar e supervisionar os trabalhadores em cargos de gestão/liderança. Já das entidades sindicais espera-se o fomento e desenvolvimento de ações informativas, tais como palestras e folhetos, mas também de apoio e suporte aos 
trabalhadores que se identificam como alvos desse tipo de violência, seja psicológico, jurídico e/ou frente a gestão da organização.

A gestão das organizações tem responsabilidade sobre o assédio que ocorre relacionado ao trabalho que ocorre, pois definem as políticas e práticas de gestão de pessoas. Inserem-se na égide de um sistema no qual o sucesso é avaliado com base nos resultados, muitas vezes o estímulo e o reconhecimento pelo trabalho são dados pelo alcance de metas abusivas e para alcançá-las são adotadas práticas de violência ou assédio moral como forma de submeter, disciplinar e controlar o trabalho humano alienado.

\section{CONSIDERAÇÕES FINAIS}

Esta pesquisa propôs uma abordagem específica para o estudo da ocupação profissional dos trabalhadores de transporte coletivo urbano sobre assédio moral no trabalho, visto que essa violência tem se tornado frequente e é identificada como prática recorrente no contexto laboral. Além disso, a existência de assédio moral no trabalho traz consequências aos indivíduos diretamente envolvidos, ao grupo de trabalho, à organização e até mesmo a categoria profissional. Os resultados demonstraram a diferença entre o quantitativo de trabalhadores identificados como vítimas por meio das respostas aos itens que demonstram comportamentos hostis mensurados pela escala utilizada e aqueles que se autorreconhecem como alvos. Além disso, a análise sobre o conhecimento da categoria acerca do AMT indica falta de informação e simplificação do fenômeno. Tais resultados demandam direcionamento da empresa e do sindicato para que trabalhadores reconheçam as verdadeiras situações de assédio moral e instrumentalizem os ambientes para prevenir, receber relatos de incidentes, oferecer apoio às vítimas e promover uma cultura de ajuda mútua entre colegas e com as chefias.

Para além dos dados quantitativos e das informações advindas da abordagem qualitativa, há que se reiterar que mesmo que o assédio não se constitua em uma forma de violência recente, tem se intensificado nos últimos anos. As alterações nas formas de organização do trabalho e, especialmente, nas condições de trabalho, se tornam propícias a cobranças excessivas por resultados, controle do tempo e das atividades, que coadunam com resultados encontrados nesta pesquisa.

Dentre os cuidados para se interpretar os resultados tem-se o fato de terem sido baseados em autorrelatos - um método amplamente utilizado, mas com potencial de vários vieses - ou seja, a autopercepção, a recordação e a experiência podem ter influenciado as respostas dos participantes. Somado a isso, tratou-se de amostra de conveniência e composta apenas por associados ao sindicato o que revela a possibilidade de dados tendenciosos pois, provavelmente, tenham participado apenas os trabalhadores dispostos a discutir o assédio moral no trabalho, bem como profissionais com certo engajamento 
político e com a categoria, apesar disso a amostra representativa sugere uma evidência da realidade. Pesquisas futuras podem ampliar a abrangência geográfica dessa pesquisa ao estudar outras cidades e/ou capitais, utilizar diferentes instrumentos que permitam comparar os resultados aqui obtidos e recorrer a um procedimento de amostragem aleatório.

\section{REFERÊNCIAS}

Alves, C. S., \& Paula, P. S. (2009). Violência no trabalho: Possíveis relações entre assaltos e TEPT em rodoviários de uma empresa de transporte coletivo. Cadernos Psicologia Social do Trabalho, 12(1), 35-46. doi:10.11606/issn.1981-0490.v12i1p35-46

Assunção, A. A., \& Medeiros, A. M. de. (2015). Violência a motoristas e cobradores de ônibus metropolitanos. Revista de Saúde Pública, 49(11), 1-10. doi:10.1590/S00348910.2015049005380

Bardin, L. (2011). Análise de conteúdo (7a ed.). São Paulo, SP: Edições 70.

Barreto, M. M. S. (2000). Uma jornada de humilhações (Dissertação de Mestrado). Pontifícia Universidade Católica de São Paulo, São Paulo, Brasil.

Barreto, M. (2006). Violência, saúde e trabalho: Uma jornada de humilhações. São Paulo: Educ.

Barreto, M., \& Heloani, R. (2014). O assédio moral como instrumento de gerenciamento. In C. G. Bottega, A. R. C. Merlo, \& K. V. Perez (Eds.), Atenção à saúde mental do trabalhador: Sofrimento e transtornos relacionados ao trabalho (pp. 52-74). Porto Alegre: Evangraf.

Barreto, M., \& Heloani, R. (2015). Violência, saúde e trabalho: A intolerância e o assédio moral nas relações laborais. Serviço Social \& Sociedade, (123), 544-61. doi:10.1590/0101-6628.036

Battiston, M., Cruz, R. M., \& Hoffmann, M. H. (2006). Condições de trabalho e saúde de motoristas de transporte coletivo urbano. Estudos de Psicologia, 11(3), 333-43. doi:10.1590/s1413$294 \times 2006000300011$

Benfatti, X. D., \& Dantas, L. M. R. (2017). A intensificação e precarização do trabalho: Um estudo bibliográfico sobre seu sentido na contemporaneidade. Revista Humanidades, 32(1), 82-93. doi:10.5020/23180714.2017.32.1.82-93

Blanch Ribas, J. M. (2003). Trabajar en la modernidad. In J. M. Blanch Ribas, M. J. E. Tomaz, \& C. G. Dorán. (Eds.). Teoría de las relaciones laborales fundamentos. Barcelona: UOC.

Borges, L. O., \& Yamamoto, O. H. (2014). Mundo do trabalho: Construção histórica e desafios contemporâneos. In J. C. Zanelli, J. Borges-Andrade, \& A. V. B. Bastos (Eds.). Psicologia, organizações e trabalho no Brasil (pp. 25-72). (2a ed.). Porto Alegre, RS: ArtMed.

Chappell, D., \& Di Martino, V. (2006). Violence at work (3a ed.). Geneva: ILO.

Couto, M. T., Lawoko, S, \& Svanstrom, L. (2009). Violence against drivers and conductors in the road passenger transport sector in Maputo, Mozambique. African Safety Promotion: A Journal of Injury and Violence Prevention, 72), 17-36. doi:10.4314/asp.v7i2.70414

Dejours, C. (2007). A banalização da injustiça social. (7a ed.). Rio de Janeiro: FGV.

Einarsen, S., Hoel, H., Zapf, D., \& Cooper, C. (2011). Bullying and harassment in the workplace: Developments in theory, research, and practice (2a ed.). Boca Ratón: CRC Press.

Espinosa, L. M. C., Cantera, F. M., \& Pallarès, S. P. (2015). Violência no trabalho: Alguns aportes relacionados ao assédio moral no trabalho. In M. L. Emmendoerfer, S. da R. Tolfo, \& T. S. Nunes (Eds.), Assédio moral em organizações públicas e a (re)ação dos sindicatos (pp. 1930). Curitiba, PR: CRV.

Freitas, L. G. de (2013). Centralidade do trabalho. In F. de O. Vieira, A. M. Mendes, \& Á. R. C. Merlo (Eds.), Dicionário crítico de gestão e psicodinâmica do trabalho (pp. 77-81). Curitiba, PR: Juruá.

Freitas, M. E. de. (2001). Assédio moral e assédio sexual: Faces do poder perverso nas organizações. Revista de Administração de Empresas, 41(2), 8-19. doi:10.1590/S003475902001000200002

Freitas, M. E., Heloani, R., \& Barreto, M. (2008). Assédio moral no trabalho. São Paulo, SP: Cengage Learning.

Gaulejac, V. de. (2007). Gestão como doença social: Ideologia, poder gerencialista e fragmentação social. São Paulo, SP: Ideias e Letras. 
Geoffrion, S., Goncalves, J., Sader, J., Boyer, R., Marchand, A., \& Guay, S. (2017). Workplace aggression against healthcare workers, law enforcement officials, and bus drivers: Differences in prevalence, perceptions, and psychological consequences. Journal of Workplace Behavioral Health, 32(3), 172-89. doi:10.1080/15555240.2017.1349611

Glasø, L., Bele, E., Nielsen, M. B., \& Einarsen, S. (2011). Bus drivers' exposure to bullying at work: An occupation-specific approach. Scandinavian Journal of Psychology, 52(5), 484-93. doi:10.1111/j.1467-9450.2011.00895.x

Gonçalves, J., \& Oliveira, R. T. de. (2017). Assédio moral no trabalho: Aspectos fundamentais de entendimento e enfrentamento. In R. T. de Oliveira, S. da R. Tolfo, L. A. Künzle, F. da C. Zanin, \& C. M. F. Prisco (Eds.) Assédio moral no trabalho: Fundamentos e ações (pp. 23-49). Florianópolis, SC: Lagoa.

Heloani, R., \& Barreto, M. (2018). Assédio moral: gestão por humilhação. Curitiba, PR: Juruá.

Hirigoyen, M. F. (2004). Lugar de trabajo. In J. Sanmartín (Ed.), El labirinto de la violência: Causas, tipos y efectos (pp. 111-22). Barcelona: Ariel.

Hirigoyen, M. F. (2008). Assédio moral: A violência perversa no cotidiano (10a ed.). Rio de Janeiro, RJ: Bertrand Brasil.

Hirigoyen, M. F. (2015). Mal-estar no trabalho: Redefinindo o assédio moral. (8a ed). Rio de Janeiro, RJ: Bertrand Brasil.

Jacoby, A. R., \& Monteiro, J. K. (2014). Mobbing of working students. Paidéia, 24(57), 39-47. doi:10.1590/1982-43272457201406

Kornig, C., Chanut-Guieu, C., Domette, L., Louit-Martinod, N., \& Méhaut, P. (2017). How french bus drivers, managers and unions talk about incivility and physical and verbal assaults at work. Psychosocial Health, Work and Language: International Perspectives Towards Their Categorizations at Work (pp. 1-197). doi:10.1007/978-3-319-50545-9

Leymann, H. (1990). Mobbing and psychological terrors at work. Violence and Victims. 5(2), 119-26.

Leymann, H. (1996). The content and development of mobbing at work. European Journal of Work and Organizational Psychology, 5(2), 165-84. doi:10.1080/13594329608414853

Lincoln, R., \& Gregory, A. (2015). Moving violations: A study of incivility and violence against urban bus drivers in Australia. International Journal of Education and Social Science, 2(1), 118127.

Martins, M. do C., \& Ferraz, A.M. S. (2014). Assédio moral no trabalho. In M. M. M. Siqueira (Ed.). Novas medidas do comportamento organizacional: Ferramentas de diagnóstico e de gestão (pp. 25-37). Porto Alegre, RS: Artmed.

Nogueira, R. M., Nunes, T. S., Carvalho Neto, A., \& Ferreira, R. R. (2019) sistematização legislativa do assédio moral no trabalho no âmbito das administrações públicas estaduais no Brasil. Revista Ciências Administrativas, 25(4), 1-19. doi:10.5020/2318-0722.2019.8011

Nunes, T. S. (2016). A influência da cultura organizacional na ocorrência do assédio moral no trabalho na Universidade Federal de Santa Catarina. (Tese de Doutorado). Universidade Federal de Santa Catarina, Florianópolis.

Nunes, T. S., Tolfo, S. da R., \& Espinosa, L. M. C. (2018). Assédio moral no trabalho: A compreensão dos trabalhadores sobre a violência. Revista de Gestão e Secretariado, 9(2), 205-219. doi:10.7769/gesec.v9i2.629

Nunes, T. S., Tolfo, S. R., \& Nunes, L. S. (2014). Assédio moral no trabalho em universidade sob a perspectiva dos observadores da violência. Revista de Carreiras e Pessoas (ReCaPe), 4(2), 166-176.

Nunes, T., \& Tolfo, S. (2013). A dinâmica e os fatores organizacionais propiciadores à ocorrência do assédio moral no trabalho. Revista de Gestão e Secretariado, 4(2), 90-113. doi:10.7769/gesec.v4i2.161

Organização Internacional do Trabalho. (2017). Informe V. Acabar con la violencia y el acoso contra las mujeres y los hombres en el mundo del trabajo. Disponível em: https://www.lo.org

Organização Internacional do Trabalho. (2019). Informe Violence and Harassment Convention, (No. 190). Disponível: https://www.ilo.org

Organização Mundial da Saúde. (2017). Hoja informativa: Salud mental en el lugar de trabajo. Disponivel em: https://www.who.int

Paes-Machado. E., \& Levenstein, C. (2002). Assaltantes a bordo: Violência, insegurança e saúde no trabalho em transporte coletivo de Salvador, Bahia, Brasil. Cadernos de Saúde Pública, 18(5), 1215-27. 
Pooli, A. M., \& Monteiro, J. K. (2018). Assédio moral no judiciário: Prevalência e repercussões na saúde dos trabalhadores. Revista Psicologia: Organizações e Trabalho, 18(2), 346-53. doi:10.17652/rpot/2018.1.13516

Rai, A., \& Agarwal, U. A. (2018). A review of literature on mediators and moderators of workplace bullying: Agenda for future research. Management Research Review, 41(7), 822-59. doi:10.1108/MRR-05-2016-0111.

Rigotto, R. M., Maciel, R. H., \& Borsoi, I. C. F. (2010). Produtividade, pressão e humilhação no trabalho: Os trabalhadores e as novas fábricas de calçados no Ceará. Revista Brasileira de Saúde Ocupacional, 35(122), 217-28. doi:10.1590/s0303-76572010000200005

Rodrigues, M., \& Freitas, M. E. de. (2014). Assédio moral nas instituições de ensino superior: Um estudo sobre as condições organizacionais que favorecem sua ocorrência. Cadernos EBAPE.BR, 12(2), 284-301.

Rueda, F. J. M., Baptista, M. N., \& Cardoso, H. F. (2015). Construção e estudos psicométricos iniciais da Escala Laboral de Assédio Moral (ELAM). Avaliação Psicológica, 14(1), 33-40.

Sampaio, R. F., Coelho, C. M., Barbosa, F. B., Mancini, M. C., \& Parreira, V. F. (2009). Work ability and stress in a bus transportation company in Belo Horizonte, Brazil. Ciência \& Saúde Coletiva, 14(1), 287-96. doi:10.1590/S1413-81232009000100035

Silveira, L. S. da, Abreu, C. C. de, \& Santos, E. M. dos. (2014). Análise da situação de trabalho de motoristas em uma empresa de ônibus urbano da cidade de Natal/RN. Psicologia: Ciência e Profissão, Brasília, 34(1), 158-79. doi:10.1590/s1414-98932014000100012

Soboll, L. A. P. (2015). Assédio moral no trabalho. In P. F. Bendassolli, \& J. E. Borges-Andrade (Eds.), Dicionário de psicologia do trabalho e das organizações (pp. 85-94). São Paulo, SP: Casa do Psicólogo.

Soboll, L. S. P. (2017). Assédio moral e organizacional na perspectiva psicossocial: Critérios obrigatórios e complementares. In L. S. P. Soboll, Intervenções em assédio moral e organizacional (pp. 13-22). São Paulo, SP: LTr.

Tolfo, S. da R. (2015). Significados e sentidos do trabalho. In P. F. Bendassolli, \& J. E. BorgesAndrade (Eds.), Dicionário de psicologia do trabalho e das organizações (pp. 617-26). São Paulo, SP: Casa do Psicólogo.

Tolfo, S. R. (2011). O assédio moral como expressão da violência no trabalho. In M. Souza, F. Martins, \& J. N. G. Araújo (Eds.), Dimensões da violência: Conhecimento, subjetividade e sofrimento psíquico (pp. 187-206). São Paulo, SP: Casa do Psicólogo.

Zhou, B., Boyer, R., \& Guay, S. (2018). Dangers on the road: A longitudinal examination of passenger-initiated violence against bus drivers. Stress and Health, 34(2), 253-65. doi:10.1002/smi.2779

\section{CONFLTTOS DE INTERESSES}

Não há conflitos de interesses.

\section{FINANCIAMENTO}

Este trabalho foi realizado com o apoio da Coordenação de Aperfeiçoamento de Pessoal de Nível Superior (CAPES), por meio de bolsa de doutorado CAPES-DS - Código de Financiamento 001 fornecida a primeira autora.

\section{SOBRE OS AUTORES}

Júlia Gonçalves é psicóloga pela Universidade Franciscana, Mestre em Psicologia pela Universidade Federal de Santa Maria, e Doutora em Psicologia pela Universidade Federal de Santa Catarina. Docente do Programa de Pós-Graduação (PPGP) e da Graduação em Psicologia da IMED.

E-mail: juliapsi@@hotmail.com

(1) https://orcid.org/0000-0002-2804-1045

Suzana da Rosa Tolfo é psicóloga e Mestre em administração pela Universidade Federal de Santa Catarina, e Doutora em Administração pela Universidade Federal de Rio Grande do Sul. Professora do Programa de Pós-Graduação em Psicologia da UFSC. 
E-mail: srtolfo14@gmail.com

\section{(1) https://orcid.org/0000-0002-6321-6496}

Leonor María Cantera Espinosa é psicóloga pela Universidade de Porto Rico e Universidade de Almería. Mestre Psicologia Comunitária pela Universidade de Porto Rico e em Autoconhecimento, Sexualidade, Relações humanas pela Universidade de Alcalá. Doutora em Filosofia pela Universidade de Porto Rico e Doutora em Psicologia Social com Prêmio Extraordinário da Universidade Autônoma de Barcelona. Professora Titular e Diretora do Departamento de Psicologia Social da Faculdade de Psicologia na Universidade Autônoma de Barcelona.

E-mail: leonor.cantera@uab.cat

(1) https://orcid.org/0000-0002-4541-5993

Thiago Soares Nunes é bacharel em administração, Mestre e Doutor em Administração pela Universidade Federal de Santa Catarina (UFSC) e Pós-Doutor em Administração pela Universidade Estadual de Maringá. Professor da Graduação e do Programa de Doutorado e Mestrado em Administração da Universidade FUMEC e do Mestrado Profissional em Administração do Centro Universitário UNA.

E-mail: adm.thiagosn@gmail.com

(3) http://orcid.org/0000-0002-1323-8160 